Geografia e Ordenamento do Território, Revista Electrónica

Centro de Estudos de Geografia e Ordenamento do Território

http://cegot.org

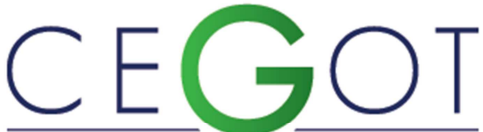

Centro de Estudos de Geografia e Ordenamento do Território
ISSN.2182-1267

Medeiros, S.

Universidade Federal do Rio Grande do Norte / Brasil

saramedeiros@ufrnet.br

\title{
Política habitacional e segregação: o Estado reproduzindo as ações do mercado
}

Referência: Medeiros, S. (2013). Política habitacional e segregação: o Estado reproduzindo as ações do mercado. Revista de Geografia e Ordenamento do Território (GOT), n. 4 (dezembro). Centro de Estudos de Geografia e Ordenamento do Território, p. 153-176

\section{Resumo}

O artigo objetiva analisar a ação do Estado, com suas políticas habitacionais, como agente gerador de segregação, sob o prisma da teoria do desenvolvimento geográfico desigual. O caso de Natal/Brasil é significativo, dada a proporção de residências construídas em conjuntos habitacionais e a área que estes ocupam. Os dados apresentados são frutos de 4116 entrevistas realizadas em 1997/1998, nos 50 maiores conjuntos habitacionais horizontais e semiverticais, construídos pelo BNH e pela Caixa Econômica Federal. Conta com a espacialização da cronologia da construção dos conjuntos habitacionais, em que visualiza tanto a dimensão da expansão urbana quanto da diferenciação espacial.

Palavras-Chave: Desenvolvimento Geográfico Desigual; Política habitacional; Segregação; Banco Nacional da Habitação; Natal/Brasil.

\section{Abstract}

The article aims to analyze the action of the State, and its housing policies, as a causative agent of segregation from the perspective of the theory of Uneven Geographical Development. The case of Natal is significant, given the proportion of residences built in 
housing and living space they occupy. The data presented are the result of 4116 interviews conducted in 1997/1998, in 50 largest housing horizontal and halfvertical built by BNH and Caixa Economica Federal. Has the spatial chronology of urban sprawl as the spatial differentiation.

Keywords: Uneven Geographical Development, housing policy; Segregation; National Housing Bank; Natal/Brazil.

\section{Introdução}

A discussão deste artigo é pautada na política habitacional empreendida na cidade de Natal, capital do Rio Grande do Norte, a partir de meados dos anos de 1960. O caso de Natal é significativo, dada a proporção de residências construídas em conjuntos habitacionais pela ação do Banco Nacional de Habitação (BNH) e a área que esses ocupam na cidade. Após a extinção do BNH, a Caixa Econômica Federal (CEF), no início da década de 1990, construiu seis conjuntos habitacionais com mais de 100 unidades na Região Administrativa Norte, seguindo as mesmas orientações do BNH. Esses foram primordiais para a expansão urbana da cidade, sendo a gênese de diversos bairros.

O trabalho visa analisar a produção dos conjuntos em Natal, considerando que é produto da ação do Estado e geradora de segregação na cidade. Essa análise é realizada à luz do desenvolvimento geográfico desigual. A estruturação segue de uma breve discussão teórica, sobre na política habitacional brasileira com os elementos centrados na distinção da atuação das rendas salariais e no desenvolvimento urbano. No estudo de caso tem-se a preocupação tanto de tratar os processos comuns às outras cidades brasileiras (expansão urbana e segregação), quanto de mostrar as especificidades desses processos e dos diferenciais, tais como o enobrecimento dos conjuntos habitacionais em Natal. A análise é focada na produção do Banco Nacional da Habitação, por ser responsável pela produção do maior número dos conjuntos estudados. 


\section{O desenvolvimento geográfico desigual e a segregação residencial}

A teoria do desenvolvimento geográfico desigual (DGD) está presente em diversas obras de David Harvey ${ }^{1}$ (1982; 2004; 2006; 2011), em que busca compreender a relação geográfica existente face às desigualdades econômicas do capitalismo. "A organização geográfica do capitalismo internaliza as contradições na forma de valor. Isto é o que se entende pelo conceito de desenvolvimento desigual do capitalismo" (HARVEY, 1982, p. 417- tradução livre ${ }^{2}$ ).

A construção da teoria de Harvey preocupa-se, principalmente, em entender como os capitalistas e seus agentes transformam o espaço e as relações espaciais.

"Os processos de acumulação do capital não existem, obviamente, fora dos respectivos contextos geográficos e essas configurações são por natureza bastante diversificadas. Mas os capitalistas e seus agentes também têm um papel ativo e fundamental na alteração dessas configurações. Novos espaços e relações espaciais estão sendo produzidos constantemente". (Harvey, 2011, p. 120).

A teoria do desenvolvimento geográfico desigual acrescenta à discussão marxista um novo componente para entender a luta de classes, a luta pelo espaço e as desigualdades inerentes à produção do espaço. Na produção do espaço: "O que nos foi dado pela natureza há muito tempo foi substituído pelo que foi construído pelo homem. A geografia do capitalismo é cada vez mais autoproduzida". (Harvey, 2011, p. 120). Há uma produção capitalista do espaço e uma luta pelo espaço, que ocorre em diferentes escalas (Smith, 2012). A escala aqui abordada é a urbana, e como o DGD se manifesta na segregação residencial.

A primeira ponte que se estabelece entre a segregação residencial e a teoria do DGD encontra-se no papel que a produção da moradia exerce na acumulação do capital. "A

\footnotetext{
${ }^{1}$ Essa reflexão também está presente nas obras de Neil Smith (1988; 2000; 2012), não com a mesma definição de "geográfica", mas com a mesma preocupação no desenvolvimento desigual do capitalismo. As contribuições de Smith são fundamentadas, principalmente, no entendimento da relação existente entre "a desigualdade e a divisão social do trabalho" e "as escalas do fenômeno"; enquanto que as leituras de Harvey são mais exemplificativas para análise do ambiente construído e na produção do espaço urbano.

${ }^{2}$ No original: "The geographical organization of capitalism internalizes the contradictions within the value form. This is what is meant by the concept of the inevitable uneven development of capitalism."(HARVEY, 1982, p. 417).
} 
construção de espaços, bem como a criação de uma morada segura chamada casa e lar, tem um impacto tanto na terra quanto na acumulação do capital, e a produção de tais lugares se torna um grande veículo para a produção e absorção do excedente." (Harvey, 2011, p.122).

A segregação, fenômeno social, é sempre espacial, traduzido como uma seletividade de acesso desigual à cidade. "Segregação espacial quase sempre é muito fácil de verificarse: trata-se de fenômeno visível a olhos nus. A cidade é repartida - toda ela - por delimitações tanto físicas quanto simbólicas" (Valença, 2006, p. 185). Para Harvey: "diferenciações geográficas frequentemente parecem ser o que elas realmente não são: meros resíduos históricos; em vez de recursos ativamente reconstituídos dentro do modo capitalista de produção" (1982, p. 416 - tradução livre ${ }^{3}$ ).

Nosso enfoque é a segregação residencial, especificamente, o espaço residencial produzido pelas políticas habitacionais. A importância do estudo da política habitacional é defendida por Salas e Castro (1993) como essenciais no estudo sobre segregação. Marcuse $^{4}$ (2004) argumenta que o Estado, por meio da regulamentação e suas ações sobre o espaço, tem o poder de desencadear a segregação: o planejamento urbano; o ritmo de provisão de infraestrutura; os programas públicos de habitação; a construção de rodovias e outros. Marcuse (2004, p. 30) explica: "se em qualquer sociedade houver segregação ela ocorrerá com a sanção tácita, quando não explícita, por parte do estado".

A política habitacional empreendida pelo Estado fomenta e acende a segregação involuntária. Esta advém das condições que o mercado impõe, via preço da terra, o acesso diferenciado, não permitindo que os que detêm menos recursos ocupem uma determinada área da cidade. Contrapondo-se à segregação voluntária, quando se tem condições de optar onde residir na cidade (Villaça, 2001).

Lefebvre (1991, p. 94) elaborou uma distinção ainda maior para segregação, dividindo-a em três aspectos: "a segregação deve ser focalizada, com seus três aspectos, ora simultâneos, ora sucessivos: espontâneo (proveniente das rendas e das ideologias) -

\footnotetext{
${ }^{3}$ No original: "Geographical differentiations then frequently appear to be what they truly are not: mere historical residuals rather than actively reconstituted features within the capitalist mode of production". (HARVEY, 1982, p. 416)

${ }^{4}$ Marcuse (2004) só considera a segregação dos pobres, sendo contrário ao conceito de auto segregação.
} 
voluntário (estabelecendo espaços separados) - programado (sob o pretexto de arrumação e de plano)". Especificamente sobre a segregação programada, vemos que "na representação urbanística, o termo "zoning" [Zoneamento] já implica separação, segregação, isolamento nos guetos arranjados. O fato torna-se racionalidade no projeto" (Lefebvre, 1991 p. 99).

A forma como o acesso à cidade se dá e como são pautadas as políticas habitacionais promovem o acesso diferenciado ao espaço urbano. Harvey (1980) explica a diferenciação com a teoria da cidade que compara com o teatro, na qual, se fizermos uma analogia entre um lote urbano e uma poltrona, haverá três cenários a serem explorados. 1ㅇ. Não havendo custo para o ingresso, as poltronas são ocupadas de acordo com a ordem de chegada: "O primeiro que entra tem possibilidades múltiplas de escolha; o segundo tem n-1, etc., com o último não tendo qualquer escolha" (Harvey, 1980, p. 144). 2o. Se há custo de ingresso, a ocupação se dá primeiro em função do poder de compra: somente ingressarão aqueles que dispõem dos recursos necessários, eliminando os que não possuem o poder de compra. 3ำ Os preços dos assentos são diferenciados: a ocupação se dá em função do poder de compra (e do desejo de quem tem mais a pagar pelas melhores ou piores localizações, de acordo com a ordem de chegada).

Trazendo essa analogia para a política habitacional no Brasil, pautada na política da casa própria, temos o 3 o cenário configurando o acesso desigual e uma segregação involuntária direcionada pela ação do Estado que atua como um agente produtor do espaço a serviço da agenda capitalista, na qual "a noção de que o capitalismo alguma vez funcionou sem o envolvimento estreito e firme do Estado é um mito que merece ser corrigido" (Harvey, 2005, p. 92).

\section{A política habitacional no Brasil: segregação residencial e ampliação do DGD}

No Brasil há historicamente uma forte atuação do Estado no sentido de promoção da política da casa própria. Essa política não privilegia a localização da população de menor poder aquisitivo na cidade, mas o acesso ao bem: a casa. Isto porque o que determina a 
localização dos conjuntos, mesmo os produzidos pelo Estado, são os preços praticados no mercado de terras. Assim, a política habitacional que tem a habitação como mercadoria, amplia a segregação involuntária e não privilegia ações que permitam o acesso a uma moradia de boa localização, independente do poder de compra do beneficiário. Tal política de casa própria não deveria ser, por isso, a solução única e última da ação de governos populares.

Ao construir conjuntos habitacionais em áreas longínquas, nas periferias geográficas da cidade, não somente condiciona a população de menor poder aquisitivo a habitar em áreas de pouca acessibilidade e com deficiência de serviços urbanos, como reforça a ocupação da cidade "abrindo" os caminhos da urbanização. Possibilita a especulação imobiliária, com a construção de grandes vazios urbanos, ampliando o DGD.

Esse é o modelo de política utilizado massivamente no Brasil. De forma contínua e prolongada, foi o modelo de atuação do Banco Nacional da Habitação nos seus 22 anos de história (1964 a 1986). Estima-se que até o período da sua extinção, o BNH foi responsável por $25 \%$ das unidades habitacionais construídas no país (Andrade e Azevedo, 1982).

A necessidade de atrelar o acesso da moradia à aquisição da casa própria não era apenas de intuito político e ideológico (Medeiros, 2004); as implicações econômicas foram de suma importância no percurso do BNH. A começar pelo caráter de banco, colocando-se à frente como um incentivador da economia, tendo como principal meta de remunerar o capital investido com planos de reajustes das prestações, sistemas de amortização dos planos habitacionais e atuando como um banco de segunda linha. $\mathrm{Na}$ venda da mercadoria moradia, constava a intenção de conciliar o econômico e o social (Azevedo, 1982; 1990).

Bolaffi $(1983$, p. 63) aponta para um grande problema na conciliação do social e do econômico nos objetivos do BNH. A intenção de concentrar no mesmo órgão as atribuições de "gerar recursos não inflacionários, cujos investimentos fossem capazes de atenuar os efeitos da queda da renda e do aumento do desemprego" e de promover "a difusão da casa própria entre as populações urbanas de baixa renda e até eliminar-se o enorme 'déficit habitacional' que aflige as cidades brasileiras", torna-se contraditória, uma vez que a casa própria a baixo custo requer inovações no setor produtivo, 
enquanto a produção tradicional utilizada pela construção civil gera mais empregos no setor. A opção de propagação de postos de trabalho foi largamente utilizada pelo BNH, pouco se preocupando com o barateamento da mercadoria habitação (a primeira iniciativa vislumbrando novas técnicas no setor produtivo surge apenas em 1978, com o Simpósio sobre o Barateamento da Construção Habitacional, realizado na Bahia).

Para auxiliar o lado empresarial do $\mathrm{BNH}$, foi criado o Sistema Financeiro Habitacional (SFH), que captava recursos advindos do FGTS (Fundo de Garantia por Tempo de Serviço) - criado através da Lei n. 5.107, de 14 de setembro de 1966, tipo de poupança compulsória, constituída com base em $8 \%$ dos salários do mercado de trabalho formal -, e do SBPE (Sistema Brasileiro de Poupança e Empréstimo), com base no sistema de poupança voluntária ${ }^{5}$. O primeiro, o FGTS, deveria ser usado para financiar as obras destinadas à população de baixa renda, enquanto o SBPE financiaria o setor de classe média e alta (ARRETCHE, 1990; ANDRADE \&AZEVEDO, 1982). "Na verdade, a criação do SFH seria um dos elementos da constituição de um sistema financeiro nacional, capaz de intermediar o crédito e permitir a realização de financiamentos de médio e longo prazos" (ARRECTHE, 1990, p. 24).

A crítica ao modelo adotado pelo SFH passa, primeiramente, pelo abandono da questão social em benefício do desenvolvimento econômico. Atrelada ao objetivo econômico (em detrimento do social), estava a opção de financiar casas próprias e novas (com menos de 180 dias de 'habite-se'), gerando um boom no setor imobiliário, ao mesmo tempo que se desconsideravam imóveis com condições de habitabilidade e que poderiam ser disponibilizados por menor custo (ARRETCHE, 1990). Outro imperativo que favorecia a construção de novas moradias era, como já mencionamos, o de dinamizar a economia através da construção civil.

A política do BNH atuava com dois agentes operacionais: As Companhias de Habitação (COHAB's) e os Institutos de Orientação às Cooperativas Habitacionais (INOCOOP's). As COHAB's, inicialmente, atendiam a população com rendas de até três salários mínimos. Em meados de 1975, ampliara o teto para cinco salários mínimos, enquanto que os INOCOOP's se encarregavam da população de seis a doze salários mínimos. Ao

\footnotetext{
${ }^{5}$ Esses recursos só começaram a ser disponibilizados em 1967.
} 
estabelecer essa diferenciação de atuação, gerou-se uma divisão por renda e consequentemente um modo operante diferenciado. No Brasil, de modo geral, não só o padrão das unidades produzidas pelas cooperativas (com assessoria dos INOCOOPs), como a sua localização, foram melhores do que as produzidas pelas COHABs.

O BNH não operava apenas com a produção de habitação, estavam nas suas competências, operações complementares e de desenvolvimento urbano. Nos primeiros anos de atuação, o BNH sofreu criticas pela ineficiência e baixo investimentos em infraestrutura e serviços urbanos (Maricato, 1987; Bonduki, 2004). Ao longo da sua trajetória os esforços em sanar essa deficiência, levaram a uma maior dedicação de orçamento do órgão para o desenvolvimento urbano ${ }^{6}$.

Andrade e Azevedo (1982) defendem a postura tomada pelo BNH de adentrar no domínio do planejamento urbano, que não contava com um órgão de competência nacional para vislumbrar as necessidades de infraestrutura sanitária, abastecimento de água e até transporte (pautadas nas reivindicações dos moradores de vários conjuntos habitacionais). Porém, os autores criticam o modelo empresarial adotado na política habitacional e agregado, também, nesses novos campos de atuação.

"Tradicionalmente água e esgoto têm sido subsidiados pelas prefeituras municipais. Com o Plano Nacional de Saneamento (PLANASA), tais serviços, antes considerados 'bens públicos', vêm sendo privatizados, em detrimento dos setores menos privilegiados da sociedade" (Andrade e Azevedo1982, p. 84).

O modelo empresarial permitiu ampliar o DGD, impossibilitando um dos objetivos almejados pelo BNH: a promoção da melhor distribuição geográfica dos investimentos atenuando os desníveis regionais (Santos, 1999). Mesmo assim, alguns projetos, como o "Cidade de porte médio", surgiram como resposta à intensa urbanização no Brasil, já que era necessário conter o ímpeto migratório para as metrópoles. Esse projeto iniciado nos anos 1970 teve Natal como uma das cidades receptoras.

${ }^{6}$ ver BNH 1976; 1978; 1982; 1984; 1985. 


\section{A política habitacional em Natal}

A atuação da política habitacional em Natal é um estudo de caso interessante, devido a algumas especificidades: a) A expansão urbana advinda da construção dos conjuntos é expressiva, até porque antes de 1964 (início de atuação do BNH), a cidade tinha uma pequena ocupação urbana com uma vasta área a ser explorada; b) há uma elevada proporção de unidades habitacionais em conjuntos em relação às unidades habitacionais permanentes na cidade; c) houve a inserção dos conjuntos habitacionais no eixo de valorização imobiliária da cidade; b) os conjuntos habitacionais não foram apropriados por uma população de baixo poder aquisitivo, até mesmo os conjuntos de $\mathrm{COHAB}$; disto resulta o não estigma" de "pobre" para quem mora em conjunto habitacional do BNH nesta cidade.

O foco do trabalho dado ao BNH advém do fato de que durante a atuação desse órgão foram construídos os maiores conjuntos habitacionais na cidade. Para dar suporte a essa análise, contamos com um levantamento realizado em 1997/1998, coordenado pelo Prof. Dr. Márcio Moraes Valença, onde foram realizadas 4116 entrevistas nos 50 maiores conjuntos habitacionais (empreendimentos com mais de 100 unidades), horizontais e semiverticais, construídos até aquele período na Grande Natal abrangendo as cidades de Natal, Extremoz, São Gonçalo do Amarante e Parnamirim. De relevância significativa pelo fato de que não há dados isolados para os conjuntos, mesmo no nível dos setores censitários - que não obedecem aos limites dos conjuntos, apenas dos bairros. Os dados de 1997/1998 permitem uma leitura compartilhada com os dados dos bairros proveniente do censo de 2000 .

Contamos, ainda, com um resgate histórico construído com base em pesquisa documental nos relatórios de ações do $\mathrm{BNH}$, plantas dos projetos dos conjuntos e produções acadêmicas. Os dados receberam uma espacialização cartográfica, contribuindo com a melhor leitura e visualização da interação com outras variáveis, ampliando o nível da análise.

${ }^{7} \mathrm{O}$ termo estigma remete a um atributo profundamente depreciativo. 
Antes de adentrarmos na segregação residencial, propriamente dita, vejamos como ocorreu a expansão urbana da cidade e localização dos conjuntos habitacionais. Essa discussão dará suporte para compreender as desigualdades espaciais e sociais na cidade e como ocorreu a ocupação da periferia da cidade após os anos de 1960.

\subsection{A expansão urbana em Natal com a construção dos conjuntos habitacionais}

A respeito da expansão urbana vale frisar que o período da construção dos grandes conjuntos habitacionais (principalmente nas décadas de 1970 e 1980) é momento de intensa urbanização da cidade de Natal, em que terras que eram consideradas rurais são vendidas como glebas e loteadas, configurando a expansão do urbano na cidade, movimento usual na acumulação capitalista descrito genericamente por Harvey (2011) como a "produção do urbano".

Essa produção não é aleatória, refere-se à busca pela acumulação. "É importante reconhecer, então, que a coerência territorial e regional, que é pelo menos parcialmente visível dentro do capitalismo, é produzida ativamente em vez de passivamente recebida como uma concessão à 'natureza' ou 'história'”"8 (Harvey, 1982, p. 416 - tradução livre).

Movidos pela ideologia da casa própria, a provisão de moradias populares em Natal traçou o destino dos mais pobres situando-os em áreas geograficamente periféricas em relação ao espaço urbano já consolidado. Em Natal, os deslocamentos entre a moradia (nos conjuntos habitacionais) e o trabalho (no centro da cidade) no período da entrega das residências, acarretaram trajetos demorados e de alto custo. Mesmo os conjuntos de INOCOOP, no caso, os primeiros a serem construídos, foram localizados em áreas de precária acessibilidade. Em reportagem extraída da Revista RN Econômico, vê-se essa realidade: "Os adquirentes de casa de Neópolis, comentavam, há dez anos atrás [em referência a 1970], em bate-papo com os amigos: 'Para se ir ao conjunto é uma hora de viagem. As únicas vantagens são representadas pelas baixas prestações e pelo fato de que a casa é nossa"" (RN/Econômico, 1980, p. 63).

\footnotetext{
${ }^{8}$ No original: "It is important to recognize, then, that the territorial and regional coherence that it is at least partially discernible within capitalism is actively produced rather than passively received as a concession to 'nature' or' history'" (HARVEY, 1982, p. 416).
} 
A planta de 1958, que não apresentava a posição do mar, está sobreposta na figura 1 , tomando como referência os limites atuais da cidade. Em 1958 a cidade ocupava principalmente o que viria a ser denominado de Região Administrativa Leste e pequenas áreas da Região Oeste e Sul, a extensa área de quadras adjacentes ao centro corresponde aos bairros de Petrópolis e Tirol, construídos sobre a orientação do plano Polidrelli (Lima, 2001). A Região Norte não aparece na demarcação da Planta da cidade. É relevante observar esse momento e, a partir deste ponto, traçar um paralelo com a ocupação que houve na cidade, a partir dos anos 1960, com a construção dos conjuntos habitacionais.

Sobre a espacialização dos conjuntos na cidade, cabem as seguintes observações:

- A Região Administrativa Leste não recebeu empreendimentos habitacionais de grande porte, não sendo representada no recorte dos conjuntos com mais de 100 unidades.

- A Região Administrativa Oeste foi a primeira a receber empreendimentos deste porte (mais de 100 unidades), com os conjuntos habitacionais Cidade da Esperança (com a primeira fase realizada pela FUNDAP - Fundação do Governo do Estado, com apoio do USAID e as demais pela COHAB-RN, após a sua fundação em 1967) e Boa Vista.

- A Região Administrativa Norte foi a última área a ser ocupada pelos conjuntos, já em meados da década de 1970. 
Planta de Natal/RN no ano de 1958.

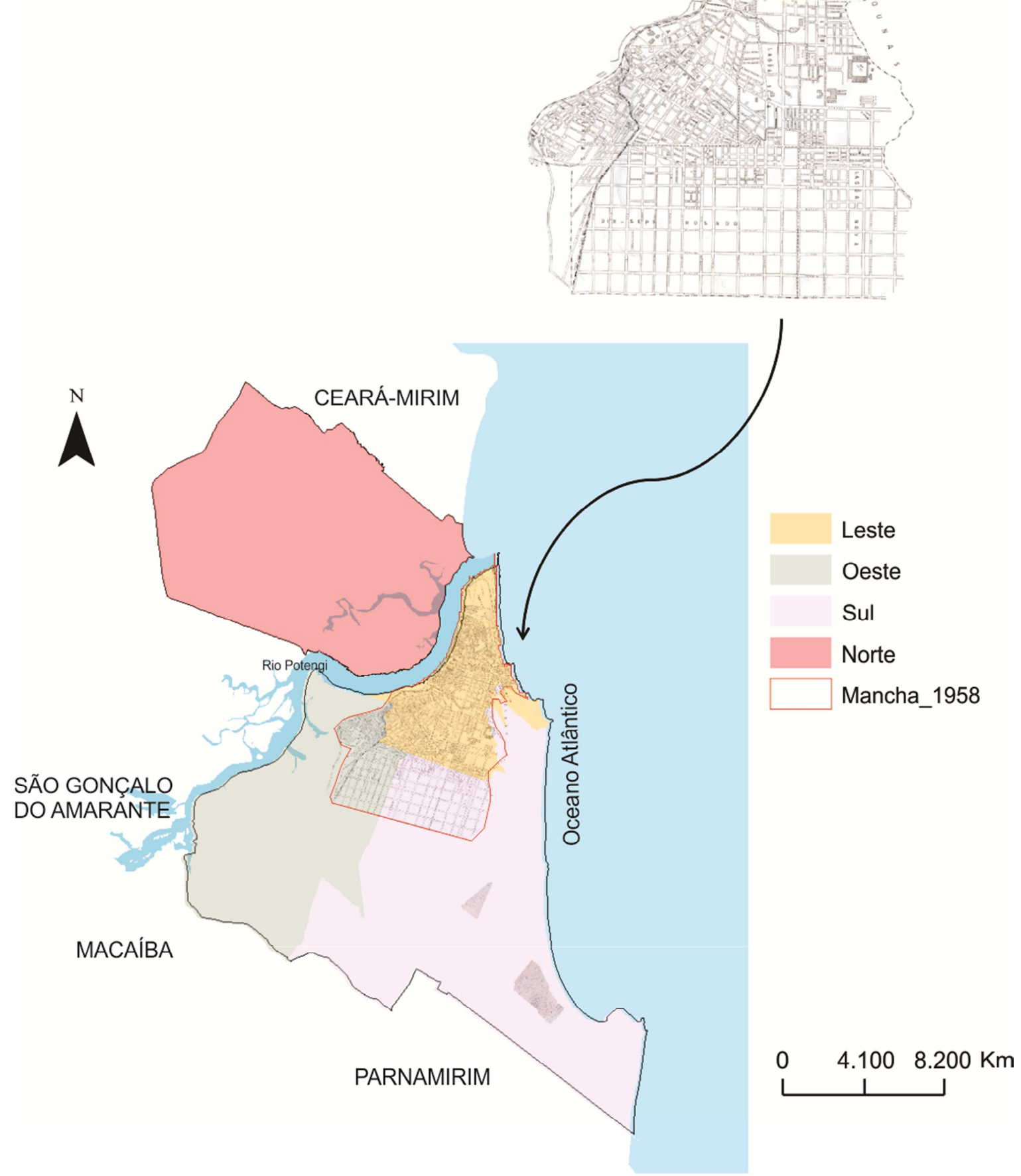

Figura 1: Natal a partir da planta da cidade no ano de 1958.

Fonte: elaboração da autora, a partir da planta disponível em Emerenciano (2007). 
A cartografia da espacialização dos conjuntos está disponibilizada na figura 2, na qual é visível a expansão urbana da cidade saindo da malha urbana delimitada na Planta da cidade de 1958 (nos mapas está indicado pelo contorno em vermelho). Saliente-se que, o agrupamento do mapa permite observar como os conjuntos habitacionais expandiram o espaço urbano da cidade.
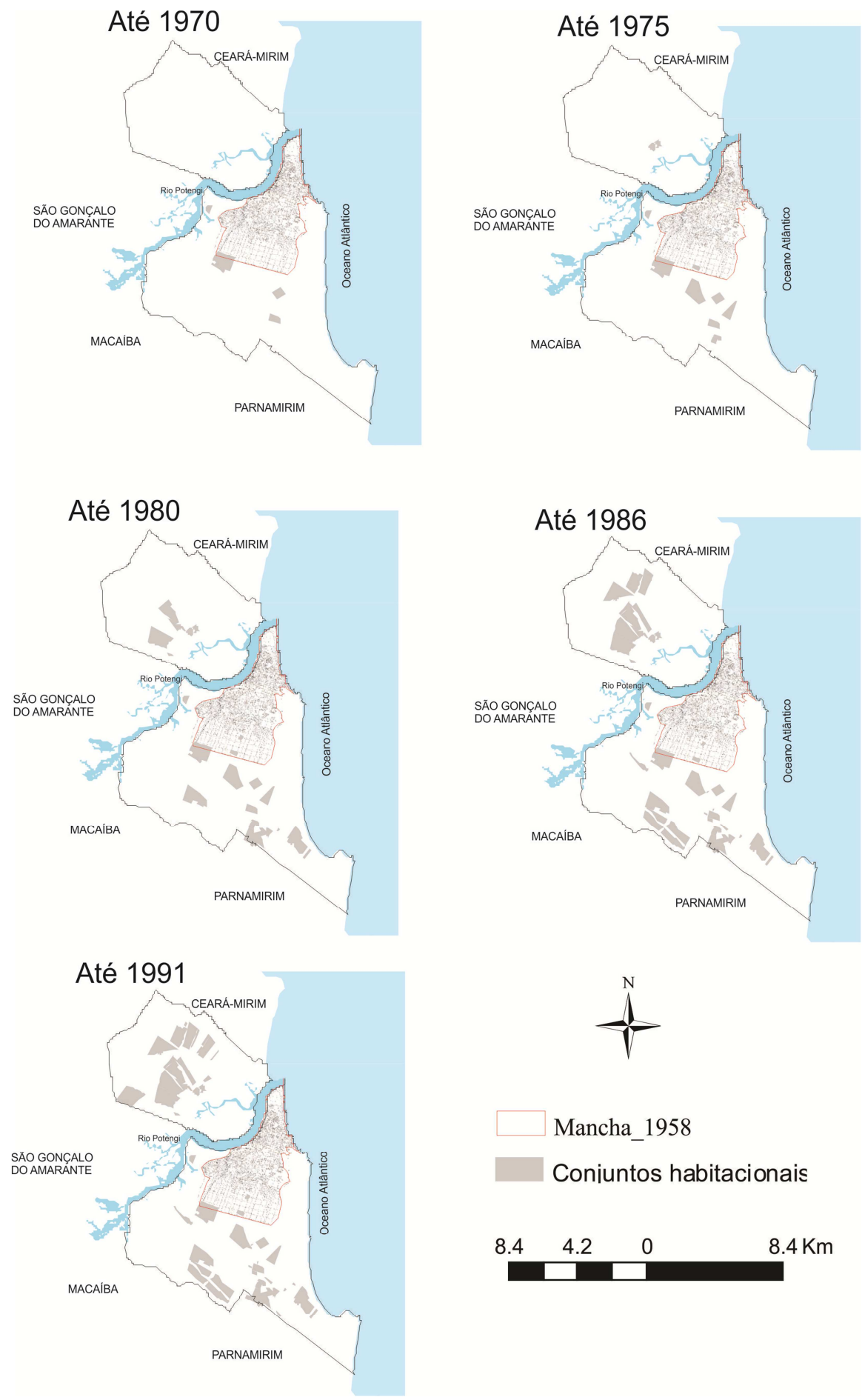

Mancha_1958

Coniuntos habitacionais

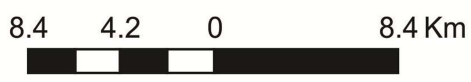

Figura 2: Os conjuntos habitacionais e a expansão urbana de Natal/RN Fonte: Elaboração da autora, com dados de Valença (1997-98). 
Essa expansão horizontal não é exclusiva da cidade de Natal: propagou-se em outras cidades. Manoel Lemes da Silva Neto (citado por Santos, 2007) lançou uma expressão apropriada para esse fenômeno: "os extensores urbanos", na seguinte correlação: "Por meio de extensores e de programas de habitação popular, a cidade aumenta desmesuradamente a sua superfície total e este aumento de área encoraja a especulação, o processo recomeçando e se repetindo e crescendo" (Santos, 2007, p. 63). A expansão urbana, por conseguinte, "a produção do espaço urbano", é a primeira estratégia lançada nas cidades para desencadear o DGD através da abertura do espaço geográfico (Harvey, 2011). Em Natal, a produção dos conjuntos habitacionais abriu as fronteiras da exploração do espaço urbano, criando os caminhos da valorização imobiliária e consequentemente da especulação. Outro fator, agregado ao processo, é a segregação do espaço residencial que dividiu a cidade por renda e por ocupação. 0 reflexo dessa segregação também é visível a partir da análise de outras variáveis.

\subsection{Os conjuntos habitacionais e a segregação residencial em Natal}

No que tange à segregação, essa se deu de forma involuntária - pelos adquirentes da casa - e programada - pelas ações do Estado que ao estabelecer dois agentes promotores, dividiu as atuações por faixas salarias. Verifica-se que o Estado age com as mesmas leis do mercado, ofertando a casa com os mesmos parâmetros de localização $X$ preço. Como fruto desse posicionamento, resultou:

- O entorno imediato da área ocupada até os anos 1960 (ver contorno estabelecido nas figuras 1 e 2) como prioritário para a implementação de conjuntos habitacionais, sendo os conjuntos Neópolis, Boa Vista e Mirassol os primeiros a serem construídos. Com o passar dos anos, devido à valorização dos terrenos nessa região, passa as ser mais significativa a atuação do INOCOOP (para população com renda acima de 5 salários mínimos).

Enquanto que:

- O "outro lado do rio" (Região Norte) tem predominantemente conjuntos da COHAB (população de 1 a 5 salários mínimos) e os conjuntos da Caixa Econômica 
Federal (CEF), que foram construídos após a extinção do BNH. A exceção é o Conjunto Parque das Dunas construído em 1990, pelo INOCOOP, na Região Norte.

A ocupação da Região Sul com os conjuntos dos INOCOOP's responde a quatro imperativos locacionais de mercado: 1) A Região Leste não dispunha de terrenos grandes para a implantação de conjuntos; 2) a Região Oeste já era ocupada por uma população de baixo poder aquisitivo; 3) a Região Sul era a via de acesso de entrada e saída da cidade para as demais capitais nordestinas e de acesso para a base militar (Parnamirim); e 4) A ocupação da Região Norte tinha a barreira geográfica do Rio Potengi, que divide a cidade em Norte e Sul, com acessos ainda precários. Esses são alguns imperativos geográficos que foram apropriados pelo mercado, traçando um quadro de valorização e desvalorização na cidade, sendo, também, determinante nas escolhas para a localização dos conjuntos de COHAB e INOCOOP. A Região Administrativa Norte passou a ser denominada como o "outro lado do rio". Essa dicotomia, de certa forma, valorizou simbólica e materialmente a Região Sul da cidade, que passou a receber mais investimentos em infraestrutura.

A figura 3 dá suporte à leitura dessa diferenciação, em que se vê a agregação dos conjuntos de INOCOOP numa mesma área da cidade, e em outra os conjuntos de COHAB e CEF.

Outros elementos que permitem visualizar a diferenciação do poder aquisitivo dos moradores dos conjuntos habitacionais são: a renda do chefe da família e o valor da prestação/aluguel. Os conjuntos dos Professores Universitários, Ponta Negra e Alagamar são os que possuem os maiores indicadores de renda. A tendência das maiores rendas segue com os conjuntos de INOCOOP e reforça a divisão Norte/Sul. Os conjuntos habitacionais com rendas menores estão localizados em bairros cujas rendas são baixas, como, por exemplo, Cidade da Esperança e Felipe Camarão. Por outro lado, o conjunto Boa Vista não corresponde à média do bairro (Nordeste) em que está inserido, nem da Região Oeste. O conjunto Boa Vista foi um dos primeiros conjuntos de INOCOOP construídos na cidade e a localização escolhida atendeu a comodidades dos funcionários da Marinha a quem se destinava. Essa tendência (rendimentos superiores dos INOCOOP's), também é visualizada nas prestações/aluguéis. Alagamar e Candelária são destaques nesse quesito. No período do levantamento, Candelária era considerada uma 
das áreas em que o metro quadrado era o mais elevado na cidade, notadamente no "Alto da Candelária", nas proximidades do conjunto habitacional.

O agrupamento por agente operacional permite eleger algumas variáveis para compreender os processos de segregação e valorização dos conjuntos habitacionais em Natal.

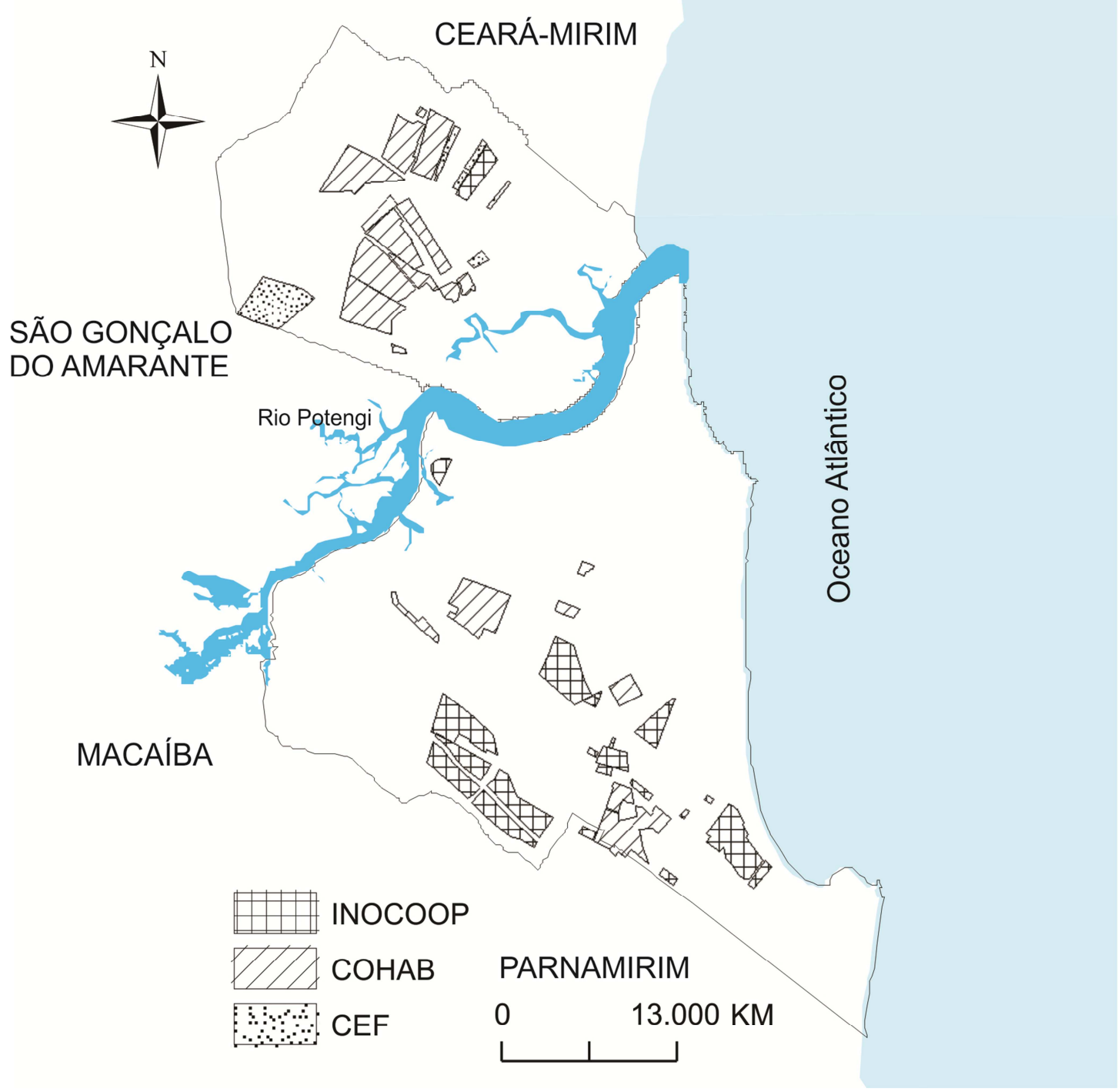

Figura 3: Espacialização dos conjuntos por agente operacional Fonte: Elaboração da autora, com dados de Valença (1997-98).

Os indicadores da quantidade de cômodos (figura 4) e quartos reforçam as análises apresentadas. Também evidenciam, como os conjuntos habitacionais de modo geral, 
possuem uma significativa área construída, com uma representatividade de unidades que possuem três quartos. Os casos de casas com mais de três quartos, é predominante nos empreendimentos de INOCOOP, com a exceção, já apresentada na localização, do conjunto Parque das Dunas que, mesmo sendo INOCOOP, se localiza em uma área de menor poder aquisitivo e segue a tendência da tipologia dos conjuntos vizinhos, com quatro cômodos, sendo entre eles, dois quartos.

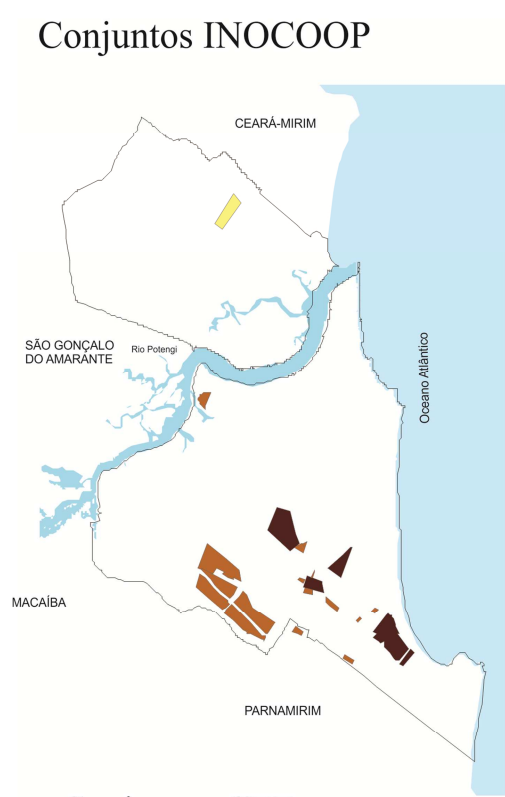

Conjuntos COHAB

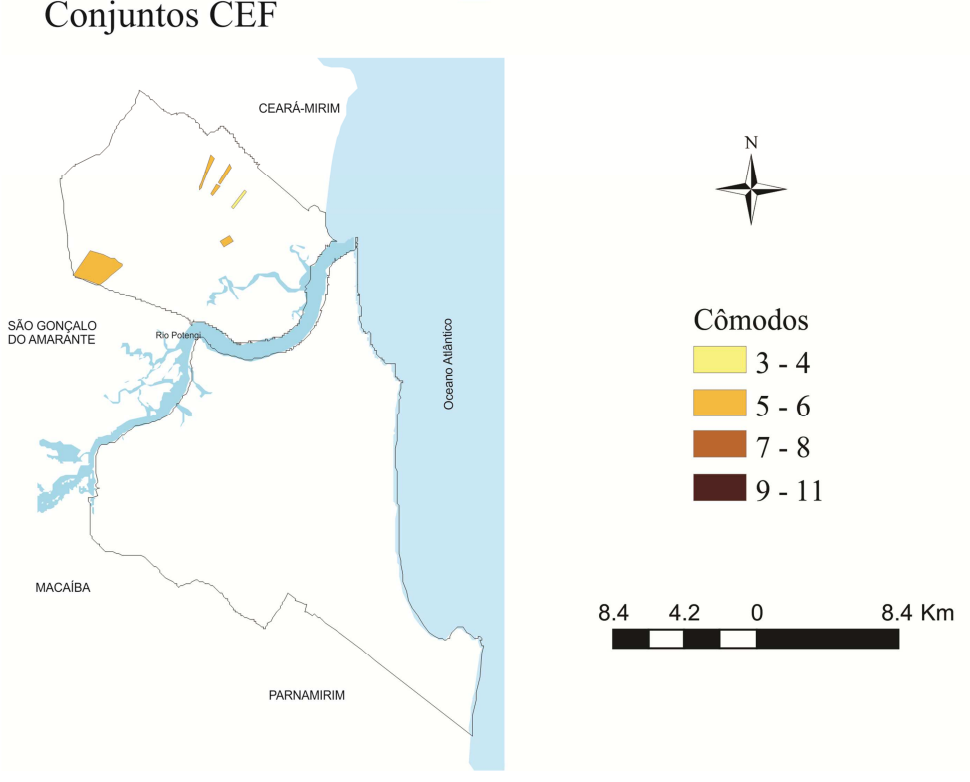

Figura 4: Espacialização dos cômodos

Fonte: Elaboração da autora, com dados de Valença (1997-98). 
É relevante, ainda, observar que os conjuntos de COHAB não possuem uma considerável área construída, sendo os mais antigos, os que possuem de sete a oito cômodos. De modo geral, os construídos nos anos 1980 são os que possuem menores dimensões. Isso também é verificado nos conjuntos da $C E F$, nos quais não se verifica casas com mais de seis cômodos. A tendência foi a diminuição do tamanho das áreas construídas por todos os agentes operacionais, não cabendo a máxima de que, apenas os conjuntos destinados à população com mais de seis salários mínimos eram dotados de maior área construída. Esse é um traço diferencial da política habitacional empreendida em Natal. Essa diferenciação será mais bem abordada no item seguinte.

\subsection{O efeito diferencial do enobrecimento nos conjuntos habitacionais em}

\section{Natal}

Até aqui, tratamos os processos decorrentes da segregação em Natal, mostrando as especificidades geográficas que levaram ao desenvolvimento geográfico desigual. Ao mesmo tempo, mostramos um cenário que não é exclusivo e que muito se assemelha a outras cidades brasileiras (notadamente as capitais) que foram alvo das ações do BNH. No entanto, em Natal há uma especificidade, dada a sua escala, de valorização dos conjuntos habitacionais. Em outras cidades brasileiras, um ou outro conjunto passou por essa valorização, mas em Natal, poucos são os conjuntos que não se tornaram valorizados. Na figura 5 são exibidos os conjuntos com rendas superiores à média do bairro, ou seja, a maioria. O enobrecimento dos conjuntos não ocorreu apenas com os conjuntos de INOCOOP's. Como anunciamos anteriormente, em Natal, quem mora em conjunto habitacional não tem estigma de pobre. Essa valorização dos conjuntos dá-se por diversos motivos, dentre eles a inserção no eixo de valorização da cidade.

Por mais que os conjuntos tenham sido localizados perifericamente em relação à área urbana já ocupada até aos anos 1960, a provisão de infraestruturas, equipamentos e serviços, ocorreu ligando os conjuntos às demais áreas da cidade. Em Natal, a cartografia dos equipamentos coletivos evidencia o quanto os conjuntos habitacionais foram receptores de escolas, unidades de saúde, segurança pública e equipamentos desportivos, perdendo apenas para as áreas da região leste (principalmente no quesito saúde, onde forma-se o corredor da saúde privada, com clínicas e hospitais 
especializados) e Oeste (notadamente nas áreas de ocupação mais antiga). Nos dados disponibilizados pela Secretaria Municipal de Meio Ambiente e Urbanismo (SEMURB) (figura 6), é nítida a convergência desses equipamentos na área de ocupação mais antiga e nos conjuntos habitacionais, deixando grandes vazios no provimento desses equipamentos.

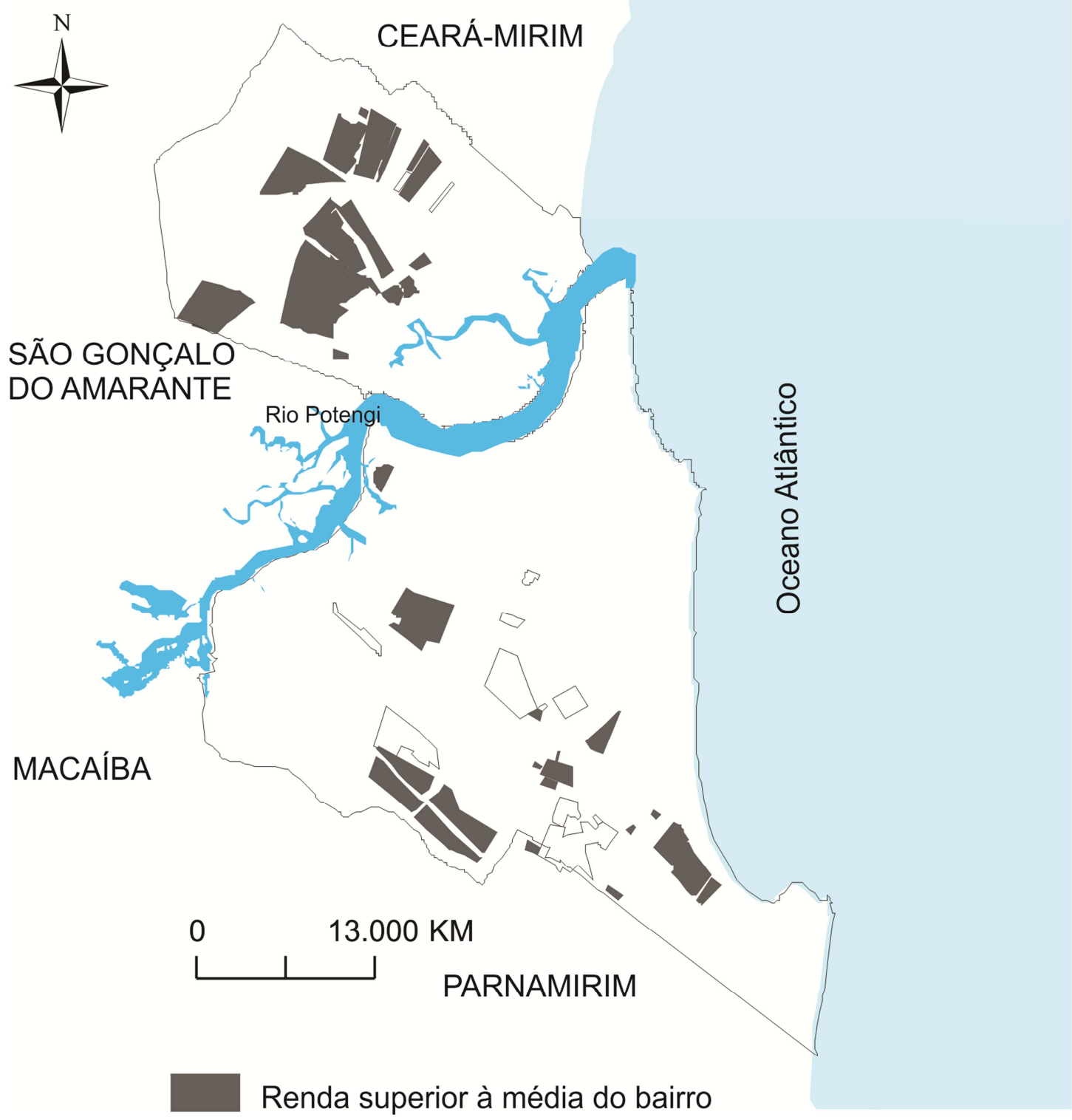

Figura 5: Conjuntos habitacionais com renda superior à média do bairro Fonte: Elaboração da autora, com dados de Valença (1997-98) e Censo do IBGE de 2000. 


\section{Escolas}

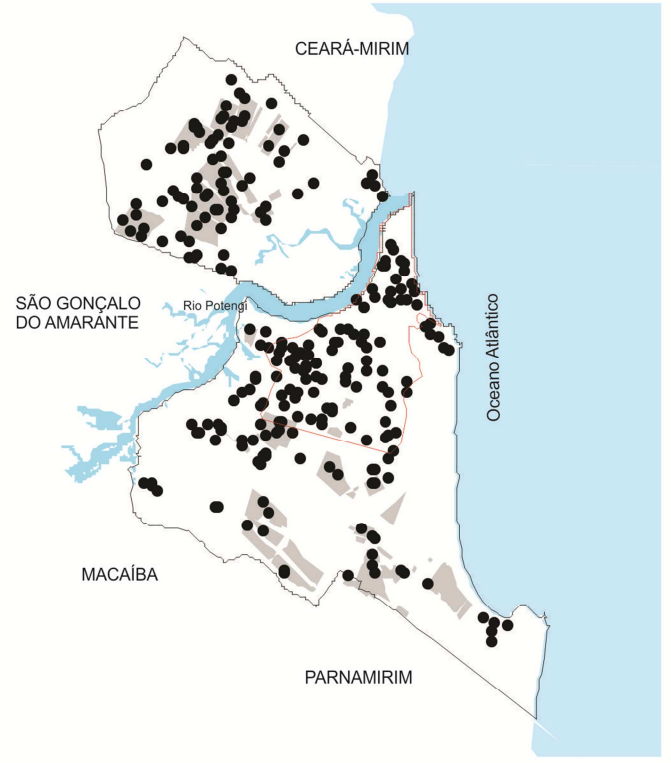

Equipamentos Desportivos
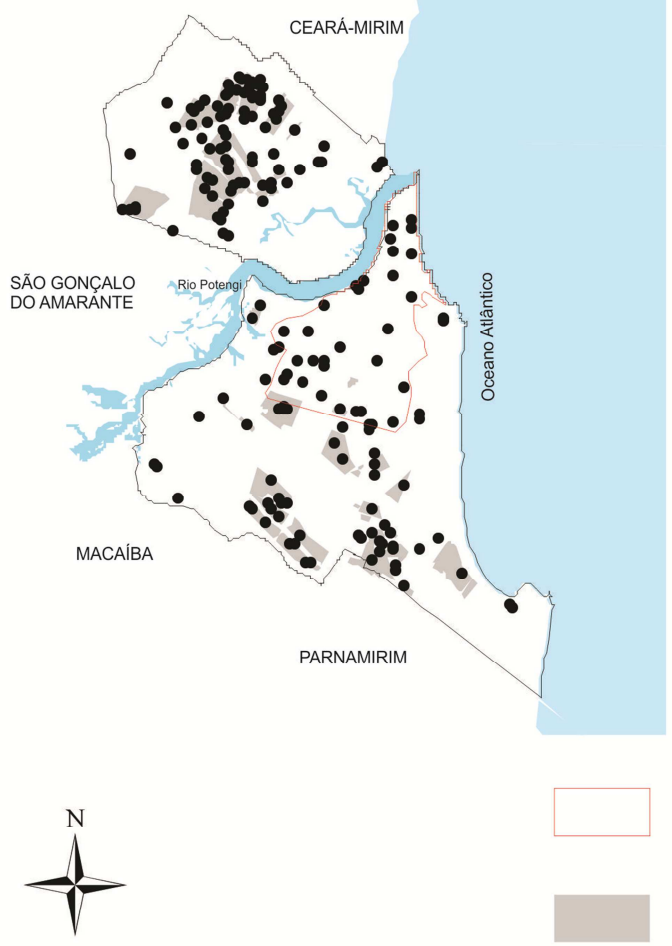

0

2.7

\section{Unidades de Saúde}

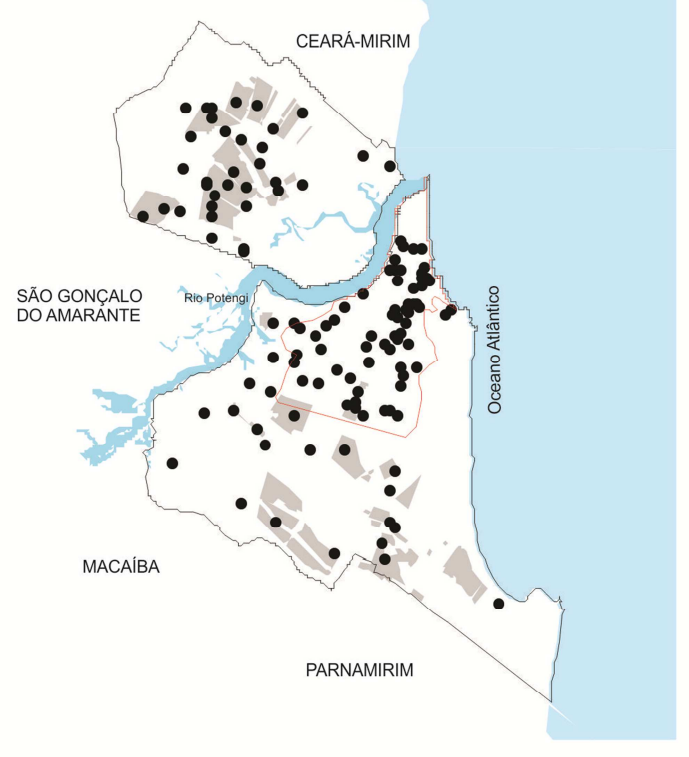

Segurança Pública

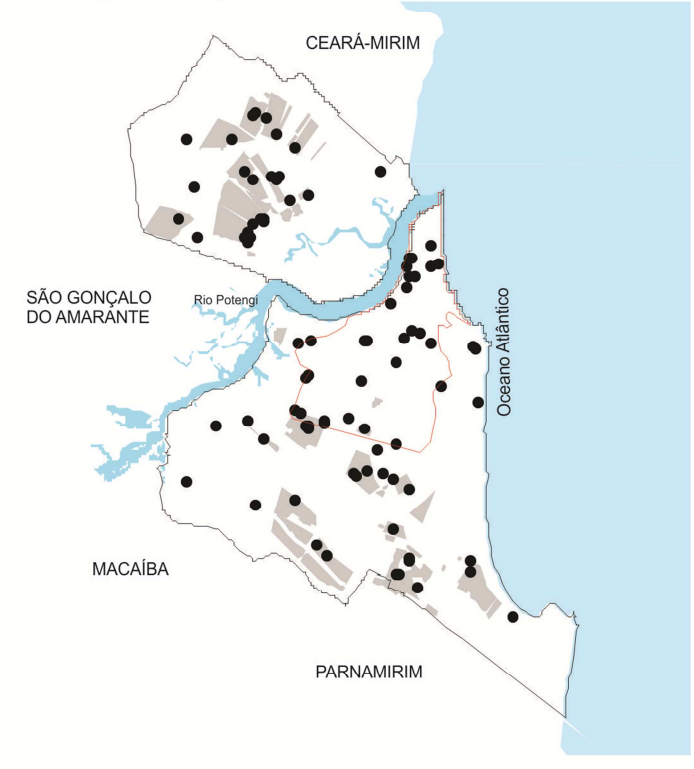

Mancha urbana 1960

Conjuntos Habitacionais

- Localização dos equipamentos

Figura 6: Espacialização dos equipamentos coletivos na cidade de Natal/RN Fonte: Elaboração da autora, com dados da SEMURB (2009).

Alguns elementos geográficos e econômicos (ligados a setores de serviço, por exemplo) podem ser explorados para compreender melhor as especificidades de cada conjunto, no que pese a maior ou menor valorização dentro da mesma Região Administrativa, do 
mesmo bairro e até mesmo no espaço interno do Conjunto. É notório, no caso dos conjuntos de Ponta Negra e Alagamar, a influência da proximidade com a praia de Ponta Negra, umas das áreas que sofreu forte valorização e influência turística. O mesmo ocorreu com os conjuntos habitacionais Candelária e Lagoa Nova que estão localizados na proximidade do Centro Administrativo do Estado, como também com o conjunto dos Professores Universitários e a relação de acessibilidade à Universidade Federal do Rio Grande do Norte. Essa é a linha de raciocínio que permite entender porque alguns conjuntos habitacionais apresentam rendas baixas, tendo esses, sido projetados e executados com a mesma proposta que os demais. Destacamos aqui o caso do conjunto Nova Natal que se assemelha à imagem de conjunto de BNH estereotipado no Brasil, muito diferente dos outros conjuntos da cidade. No entanto, é mais valorizado do que o seu entorno imediato (o bairro em que se insere), pois disputa os limites com loteamentos irregulares, informais e favelas.

A análise sobre o prisma do DGD viabiliza compreender que o processo de enobrecimento ocorrido, é parte da segregação programada (Lefebvre, 1991), uma vez que é fruto da intervenção do Estado na promoção de habitação, dividindo a atuação por agente operacional, somando-se ainda a atuação do poder público na disponibiidade de infraestrutura e equipamentos de uso coletivo. A localização desses, nos conjuntos, deve-se em grande medida, à reserva de espaço colocado no projeto de execução dos conjuntos. Cabe a ressalva de que muitos dos equipamentos coletivos que se encontram nos conjuntos habitacionais não foram providenciados no ato de entrega das moradias, pelo contrário, a espera, muitas vezes, foi longa, particularmente nos conjuntos habitacionais da COHAB.

O DGD é, igualmente, reflexo da apropriação capitalista da provisão de moradia, infraestrutura e equipamentos coletivos na cidade (Harvey, 2011). O enobrecimento (em maior ou menor medida) segue os mesmos parâmetros colocados pela segregação. Não houve uma tendência à homogeneização, houve sim, uma abertura do espaço geográfico para reprodução capitalista, fazendo emergir as desigualdades inerentes ao processo de desenvolvimento imposto pelo capital, sendo que o agente desse processo, o Estado, é justamente aquele que "deveria" minimizar essas desigualdades. 


\section{Conclusões}

A relação entre política habitacional e segregação foi apresentada levantando os argumentos que demonstram ser a ação do Estado uma sanção tácita, quando não explicita, para com o mercado (Marcuse, 2004), corrigindo o mito de que o capitalismo possa funcionar sem o envolvimento estreito e firme do Estado (Harvey, 2005). A política dos grandes conjuntos habitacionais no Brasil, trouxe novas dinâmicas urbanas para as cidades. No caso de Natal, as peculiaridades locais atreladas às regras do modelo nacional resultaram em especificidades interessantes para análise. 0 fato de ser, a cidade, um espaço totalmente aberto (com pouca área ocupada), favoreceu a execução da política habitacional e a recepção dessa, pelo mercado imobiliário local. Houve uma expansão urbana com a propagação de vazios e apropriação de infraestruturas e serviços ofertados.

Em Natal a segregação é um fenômeno visível na espacialização dos dados. As desigualdades não são fruto do acaso, mas remetem a um processo histórico de acumulação de riqueza, não sendo meros resíduos históricos (Harvey, 1982).

Evidenciar a segregação residencial como parte do desenvolvimento geográfico desigual é trazer para discussão novos elementos, que permitem ver não apenas o excluído, mas os que dispõe dos meios e condições para optar onde e como morar, traduzido como uma seletividade de acesso desigual à cidade (Valença, 2006). Aesso que ocorre pelo mercado, pelo poder de compra, haja vista a política ser de casa própria.

No caso estudado há a possibilidade de contemplar as cateogrias de renda intermediária para entender o processo de segregação, rompendo os estudos extremistas que relacionam a segregação apenas à pobreza ou riqueza (Salas e Castro, 1993). Isso porque em Natal, mesmo os moradres de conjuntos habitacionais empreendidos pelas COHAB (originalmente proposto para até cinco salários mínimos) não possuem estigmas de pobres, e em geral apresentam melhorias nas condições de moradias, principalmente os conjuntos habitacionais mais antigos, em que as casas foram ampliadas e reformadas. Não sendo essas melhorias suficientes para romper a divisão existente entre os conjuntos de COHAB e INOCOOP. O número de cômdos e quartos (um bom indicador 
para análise) nos empreendimentos do INOCOOP continuam superiores, bem como a diferenciação de renda ainda prevalecem.

O estudo apresentado evidencia que as ações do Estado, como agente em prol do capital na Política Habitacional, abrem espaço para o desenvolvimento geográfico desigual, desencadeando os processos de segregação e enobrecimento por pautarem-se nas regras de mercado e não, em medidas que levem à igualdade e à justiça social. De fato, a política empreserarial resultou no abandono da questão social em benefício do desenvolvimento econômico.

\section{Referências}

Arretche, Marta (1990). Intervenção do Estado e setor privado: o modelo brasileiro de política habitacional. Espaço e Debates, n. 31, p. 21-36.

Azevedo, Sérgio de; Andrade, Luis Aureliano Gama de (1982). Habitação e Poder: da Fundação da Casa Popular ao Banco Nacional da Habitação. Rio de Janeiro: Zahar.

Azevedo, Sérgio (1990). Housing Policy in Brazil: 1964-1986. Paper presented at the Housing Debates/Urban Challenges Conference, Paris, July.

Bolaffi, Gabriel (1983). A questão Urbana: produção de habitações, construção civil e mercado de trabalho. Novos Estudos Cebrap. São Paulo, v. 2, 1 p. 61-68, abril.

BNH (1976). Relatório de Atividades. Rio de Janeiro: Secretaria de Divulgação,

BNH (1982). Relatório Anual. Rio de Janeiro: Rio de Janeiro: Secretaria de Comunicação Social da Presidência do BNH.

BNH (1984). Relatório Anual. Rio de Janeiro: Rio de Janeiro: Secretaria de Comunicação Social da Presidência do BNH.

BNH (1985). Relatório Anual. Rio de Janeiro: Rio de Janeiro: Secretaria de Comunicação Social da Presidência do BNH.

Bonduki, Nabil (2004). Origens da habitação social no Brasil: Arquitetura moderna, Lei do Inquilinato e difusão da casa própria. 2.ed. São Paulo: Estação Liberdade: FAPESP, 343p.

Emerenciano, João Gothardo Dantas (2007). Natal Não-Há-Tal: Aspectos da História da Cidade do Natal. Natal: Secretaria de Meio Ambiente e Urbanismo, Departamento de Informação, Pesquisa e Estatística.

Harvey, David (2004). Espaços de esperança. São Paulo: Loyola.

Harvey, David (2006). Spaces of global capitalism: towards a theory of uneven geographical development. London; New York: Verso.

Harvey, David (1980). A justiça Social e a cidade. São Paulo: Hucitec.

Harvey, David (2005). A produção capitalista do espaço. São Paulo: Annablume.

Harvey, David (2011). O enigma do capital: e as crises do capitalismo São Paulo: Boitempo.

Harvey, David (1982). The Limits to Capital. Basil Blackwell .Oxford.

Lefebvre, Henri (1991). 0 direito à cidade. São Paulo: Moraes.

Lima, Pedro de (2001). Natal século XX: do urbanismo ao planejamento urbano. Natal: EDUFRN. 
Marcuse, Peter (2004). Enclaves, sim; Guetos, não: a segregação e o Estado. Espaço e Debates. São Paulo, v. 24, n. 45, jan/jul p. 87-109.

Maricato, Ermínia (1987). Política Habitacional no Regime Militar: do milagre brasileiro à crise econômica. Petrópolis: Vozes, 196 p.

Medeiros, Sara Raquel Fernandes Queiroz de (2004). Moradia X Ordem Social. Sociedade e Território. V. 16, n. 1/2, jan. dez. Natal: EDURFN.

Medeiros, Sara Raquel Fernandes Queiroz de (2007). A casa própria: sonho ou realidade? Um olhar sobre os conjuntos habitacionais em Natal. Natal: UFRN. (Dissertação de mestrado).

RN/ECONÔMICO (1980). O “Elefante” sob pressão. Editora RN/Econômico Ltda. Ano X, n.112, mai.

Salas, Minor Mora; Castro, Franklin Solano (1993). Segregacion Urbana: um acercamiento conceptual. Ciencias sociales, n. 61, setembre, p. 17-26.

Santos, Cláudio Hamilton M (1999). Políticas Federais de Habitação no Brasil: 1964/1998. IPEA, Brasília. (Texto para discussão no 654).

Santos, Milton (2007). O Espaço do cidadão. 7 ed. São Paulo: Editora da USP.

Smith, Neil (1988). Desenvolvimento desigual. Rio de Janeiro: Bertrand Brasil.

Smith, Neil (2000). Contornos de uma política especializada: Veículos dos sem-teo e produção da escala

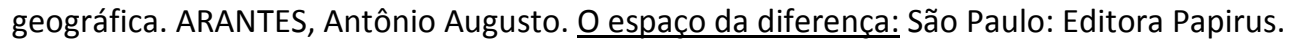

Smith, Neil (2012). La nueva frontera urbana: Ciudad revanchista y gentrificación. Madrid: Tra cantes de Sueños.

SEMURB - Secretaria Municipal de Meio Ambiente e Urbanismo (2009). Base de dados dos equipamentos coletivos. Natal: SEMURB.

Valença, Márcio Moraes (2006). Cidades ingovernáveis? Ensaio sobre o pensamento harveyano acerca da urbanização do capital. SILVA, José Borzacchiello da; LIMA, Luiz Cruz; ELIAS, Denise (orgs). Panorama da geografia brasileira. São Paulo: Annablume.

Valença, Márcio Moraes (1997/1998). Banco de Dados do projeto de pesquisa Os conjuntos habitacionais em Natal. Natal: UFRN.

Villaça, Flávio (2001). Espaço intra-urbano no Brasil. São Paulo: Studio Nobel: FAPESP Lincoln Institute. 